\title{
Health Care and Health Among Tribal Women in Jharkhand: A Situational Analysis
}

\author{
Sutapa Maiti ${ }^{1}$, Sayeed Unisa ${ }^{2}$ and Praween K. Agrawal ${ }^{3}$ \\ International Institute for Population Sciences, Deonar, Mumbai 400 088, Maharashtra, India \\ 1.E-mail: sutapaiips@rediffmail.com 2.E-mail: sayeedu@vsnl.net \\ 3. E-mail: praween_agrawal@rediffmail.com
}

KEY WORDS Tribal; non-tribal; health care; women

\begin{abstract}
The paper investigates the health care and health condition among the tribal women in comparison to the non-tribal women in the newly formed state of Jharkhand by drawing upon data from the National Family Health Survey - 2, conducted during 1998-99. The non-tribal women were better off than the tribal women in terms of standard of living, education and other socio-demographic indicators. The paper lists out antenatal, delivery and postnatal characteristics of tribal and non-tribal women, delivery and postpartum care, contraceptive use and problems and nutritional status and identifies many lacunae.
\end{abstract}

\section{INTRODUCTION}

India's tribal population, the largest in the world, was about 67.7 million in 1991. The tribal areas of concentration in India are traditionally isolated, underdeveloped and are increasingly affected by development processes (Ahmed, 1985). There is a general agreement that the health status of the tribal population in India is very poor, deficient in sanitary conditions, personal hygiene, and health education (Basu, 1994). Tribal mothers have high rates of anemia, and girl children receive less than the desired nutritional intake. All told, the whole tribal community is deficient in adequate food intake. The extent of knowledge and practice of family planning was also found to be low among the Scheduled Tribes (Kanitkar and Sinha, 1988). There is a need for proper understanding of the different health aspects of tribal women and their specific health needs so that relevant health measures can be prepared and implemented. More particularly, there is a need for undertaking a region-specific study of the health of the tribal women, which will make planning for their welfare more successful. In the above context, this study investigates the maternal health care practices and health condition among the tribal women in comparison to the non-tribal women of Jharkhand* with reference to:

* The newly created state of Jharkhand has a sizeable proportion of tribal population $(27.7 \%$ according to 1991 Census). Also the National Family Health Survey (NFHS-2, 1998-99) shows $29.1 \%$ tribal women in its total sample population of Jharkhand.
- Differentials in the socio-economic and demographic characteristic;

- Antenatal problems and care, delivery care and postnatal care;

- Current contraceptive use and reproductive health problems; and

- Nutritional and anemia status.

\section{DATA SOURCE AND METHODOLOGY}

Data are from India's second National Family Health Survey (NFHS-2) conducted in 1998-99 for the state of Jharkhand. This survey was designed on the lines of the Demographic and Health Surveys (DHS) that have been conducted in many developing countries since the 1980s. NFHS-2 collected demographic, socioeconomic, and health information from a nationally representative probability sample of 90,303 evermarried women age 15-49 residing in 92,486 households. All states of India are represented in the sample (except the small Union Territories), covering more than 99 percent of country's population. The sample is a multi-stage cluster sample with an overall response rate of 98 percent. Details of sample design, including sampling frame and sample implementation, are provided in the basic survey report for all India (IIPS \& ORC Macro, 2000). For the state of Jharkhand, NFHS-2 has collected data of a representative probability sample of 1614 evermarried women age 15-49 years residing in 1642 households (IIPS \& ORC Macro, 2001). The analysis here focuses on 1614 ever-married 
women age 15-49 years comprising of 469 tribal women and 1145 non-tribal women (including Scheduled castes, other backward class and general castes).

Maternal health care of the tribal women in comparison with the non tribal women has been investigated with reference to the health problems and health care during pregnancy, antenatal checkups, antenatal advices, reasons for not receiving antenatal checkups, problem during and after delivery, place of delivery and assistance during delivery and also the post natal health care of the mother as well as the baby. In addition to these, the situation of the tribal and non-tribal women in Jharkhand has also been seen in terms of their nutritional and anemia status, current reproductive health problems and contraceptive use and problems with the method currently in use. Simple bi-variate analysis has been done and result has been shown in percentage for different health care and health parameters.

\section{SOCIO-ECONOMIC AND DEMOGRAPHIC CHARACTERISTICS OF TRIBAL AND NON-TRIBAL WOMEN OF JHARKHAND}

Table 1 represents the percentage distribution of tribal and non-tribal women aged 15-49 years by different socio-economic and demographic attributes like age, marital status, types of place of residence, education, husband's education, standard of living, working status, lifestyle, religion, exposure to mass media and number of children ever born. Age structure shows different patterns for tribal and non-tribal women. Tribal women were slightly more in the younger cohorts than non-tribal women. About $52 \%$ of tribal women are below age 30 compared to $50 \%$ of the non-tribal women. Less than $3 \%$ of tribal women reside in urban areas compared to $23 \%$ of nontribal women. More than $80 \%$ of tribal as well as non-tribal women belong to the Hindu religion. Though over ninety percent of both tribal and non-tribal women are currently married, a considerable percentage (6.1) of tribal women also belongs to 'other' category comprising of divorced, separated and others. The mean numbers of children ever born for both the tribal and non-tribal women are almost the same.

A sizeable gap has been noticed in educational attainment between tribal and nontribal women in Jharkhand. $89 \%$ of the tribal women were illiterate compared to $71 \%$ of the non-tribal women. Only $3 \%$ of tribal women completed education above high school compared to $8 \%$ in the case of non-tribal women. Again, not only are tribal women illiterate themselves, their husband's educational status is also very poor. $62 \%$ percent of tribal women's husbands are illiterate compared to $37 \%$ among non-tribal women. Again, with respect to mass media, which plays an important role in development and utilisation of health services, $88 \%$ tribal women have not been exposed to any mass media compared to $61 \%$ among non-tribal women.

In table 1, household standard of living index (SLI) has been calculated on the basis of availability of amenities and is a proxy variable for determining the economic status of the household. There is a huge gap in SLI between tribal and non-tribal women in Jharkhand. About $12 \%$ of non-tribal women have a high standard of living compared to only $1 \%$ of tribal women. The majority of tribal women (more than $75 \%$ ) have a low standard of living, compared to only $49 \%$ of non-tribal women.

Considering the lifestyle indicators like chewing paan masala or tobacco, drinking alcohol, or smoking, it has been found that in Jharkhand, tribal women are more prone to these undesirable behaviour than their non-tribal counterparts. These lifestyle indicators are of substantial interest because the use of paan masala, tobacco, and alcohol, all have a very detrimental effect on one's health. More than $21 \%$ of tribal women are addicted to chewing paan masala or tobacco, compared to only $7 \%$ among the non-tribal women. Alcohol consumption is more than $31 \%$ among the tribal women compared to only $4 \%$ among the non-tribal women. Also, about $4 \%$ of tribal women smokes compared to only $1 \%$ of non-tribal women (Table 1 ).

\section{ANTENATAL, DELIVERY AND POSTNATAL CHARACTERISTICS}

\section{Antenatal Problems and Care}

Antenatal care (ANC) refers to pregnancyrelated health care provided by a doctor or a health worker in a medical facility or at home. The Safe Motherhood Initiative proclaims that all pregnant women must receive basic professional antenatal care (Harrison, 1990). The 
Table 1: Percentage distribution of tribal and nontribal women by selected socio-economic and demographic characteristics, Jharkhand, 1998-99

\begin{tabular}{|c|c|c|}
\hline $\begin{array}{l}\text { Socio-economic } \\
\text { and demographic } \\
\text { characteristics }\end{array}$ & $\begin{array}{l}\text { Tribal } \\
\text { women }\end{array}$ & $\begin{array}{l}\text { Non- } \\
\text { tribal } \\
\text { women }\end{array}$ \\
\hline \multicolumn{3}{|l|}{ Age Groups } \\
\hline Below 30 & 52.3 & 49.5 \\
\hline $30-40$ & 32.1 & 30.8 \\
\hline Above 40 & 15.6 & 19.6 \\
\hline \multicolumn{3}{|l|}{ Marital Status } \\
\hline Currently married & 93.9 & 95.8 \\
\hline Others & 6.1 & 4.2 \\
\hline Mean Children Ever Born & 2.2 & 2.3 \\
\hline \multicolumn{3}{|l|}{ Type of Place of Residence } \\
\hline Urban & 2.6 & 23.2 \\
\hline Rural & 97.4 & 76.8 \\
\hline \multicolumn{3}{|l|}{ Educational Attainment } \\
\hline Illiterate & 89.0 & 71.1 \\
\hline Literate, <middle school complete & 5.7 & 14.6 \\
\hline Middle school complete & 2.6 & 6.0 \\
\hline High school and above & 2.6 & 8.3 \\
\hline \multicolumn{3}{|l|}{ Husband's Education } \\
\hline Illiterate & 61.8 & 37.3 \\
\hline Literate, <middle school complete & 17.5 & 21.4 \\
\hline Middle school complete & 9.1 & 12.7 \\
\hline High school and above & 11.6 & 28.7 \\
\hline \multicolumn{3}{|l|}{ Working Status } \\
\hline Working & 41.1 & 22.8 \\
\hline Not working & 58.9 & 77.3 \\
\hline \multicolumn{3}{|l|}{ Lifestyle Indicators } \\
\hline Chew paan masala or tobacco & 21.7 & 6.6 \\
\hline Drink alcohol & 31.3 & 4.2 \\
\hline Smoke & 4.3 & 1.4 \\
\hline Not Regularly Exposed to Any Media & ia 87.8 & 61.4 \\
\hline \multicolumn{3}{|c|}{ Standard of Living Index } \\
\hline Low & 75.8 & 48.8 \\
\hline Medium & 23.2 & 38.9 \\
\hline High & 1.0 & 12.3 \\
\hline Religion & & 83.6 \\
\hline Hindu & 81.3 & 17.0 \\
\hline Others & 18.7 & \\
\hline Number of women & 469 & 1145 \\
\hline
\end{tabular}

$\mathrm{RCH}$ programme of the Government of India recommends that as part of antenatal care, women should receive two doses of tetanus toxoid vaccines, adequate amount of iron and folic acid tablets or syrups to prevent and treat anemia, and at least three antenatal checkups that include blood pressure checks and other procedures to detect pregnancy complications (Ministry of Health and Family Welfare 1997; 1998).

(i) Problems During Pregnancy: Table 2 shows the percentage of tribal and non-tribal women age 15-49 years experiencing any of the pregnancy-related problems like night blindness, blurred vision, convulsions (not from fever), swelling (of the leg, body or face), excessive fatigue, anemia or vaginal bleeding. The pregnancy-related health problems commonly reported among both the tribals and non-tribal women are excessive fatigue (49\% and $56 \%$ respectively). The second important pregnancy related problem among the tribal women in Jharkhand is swelling of legs, body or face, (49\%). $38 \%$ of tribal women reported convulsions that were not from fever, compared to $34 \%$ among the non-tribal women. The reported problem of anemia is almost same (29\%) among both the groups of women in Jharkhand. Only 2\% tribal women reported any vaginal bleeding compared to $3 \%$ non-tribal women.

(ii) Components of Antenatal Check-ups: The effectiveness of antenatal check-ups in ensuring safe motherhood depends in part on the tests and measurements done and the advice given during the check-ups. Table 3 shows the percentage of tribal and non-tribal women who have gone through several antenatal check ups at least once during their last pregnancy. The condition of non-tribal women, which includes Scheduled Castes, Other Backward Classes and general castes, is comparatively better for these six check ups. General check-up, which includes weight and height measurements, has been done by $50 \%$ of the tribal women compared to $57 \%$ among the non-tribal women. Only $37 \%$ of tribal mothers had their blood pressure checked as

Table 2: Percentage of tribal and non-tribal women with health problems during pregnancy, Jharkhand, 1998-99

\begin{tabular}{lccc}
\hline Health problems during pregnancy & Tribal women & Non-tribal women & Total \\
\hline Night blindness & 20.4 & 14.1 & 15.9 \\
Blurred vision & 33.6 & 36.0 & 35.3 \\
Convulsion (not from fever) & 38.4 & 34.1 & 35.3 \\
Swelling of the legs, body or face & 49.0 & 31.1 & 36.1 \\
Excessive fatigue & 49.3 & 55.7 & 53.9 \\
Anemia & 28.9 & 29.2 & 29.1 \\
Vaginal bleeding & 2.1 & 3.3 & 2.8 \\
Number of births & $\mathbf{1 4 2}$ & $\mathbf{3 6 8}$ & $\mathbf{5 1 0}$ \\
\hline
\end{tabular}

Note: Table includes only for the most recent birth during the three years preceding the survey 
compared to $60 \%$ of the non-tribal women. Abdomen examinations were the most frequently carried out antenatal check-up by $53 \%$ and $70 \%$ of tribal and non-tribal women respectively. Only $15 \%$ of births among tribal mothers were accompanied by an internal examination during any antenatal check-up. Again $41 \%$ of tribal mothers had undergone a blood test and only $28 \%$ had their urine test. Most of these measurements or tests were performed 1.5 times more often during antenatal check-ups for nontribal mothers than for tribal mothers. X-ray or sonography was not done at all for the tribal women. $2 \%$ of non-tribal women has undergone $\mathrm{X}$-ray and $7 \%$ had undergone sonography.

For all the items of antenatal advice, tribal women received less advice than their non-tribal counterparts (Table 3). 63\% tribal women received advice on dietary conditions during pregnancy from the health workers, whereas about $70 \%$ of non-tribal women received the same advice. Advice on danger signs during pregnancy had been received by $35 \%$ of tribal women compared to $40 \%$ of non-tribal women. About $39 \%$ of tribal women received advice on delivery care, as compared to more than $45 \%$ of non-tribal women. However advice on newborn care was received by almost the same percentage of tribal and non-tribal women. It is very distressing to note that only about $7 \%$ of tribal women received advice on family planning as against $19 \%$ of non-tribal women. While it is felt that pregnant women who utilise antenatal care services come in contact with the health staff and are thus more likely to accept family planning after child birth, in Jharkhand, a different situation prevails.

(iii) Status of TT Vaccine and Iron and Folic Acid Supplementation: In India, the tetanus toxoid immunisation programme for expectant mothers was initiated in 1975-76 and was integrated with the Expanded Programme on Immunization (EPI) in 1978 (Ministry of Health and Family Welfare 1991). Table 4 shows the antenatal check-ups, status of TT vaccine and iron and folic acid supplementation among the tribal and non-tribal women in Jharkhand. One in every four tribal women undergoes ANC compared to $44 \%$ of the non-tribal women. Again, not only is the incidence of ANC is less frequent among the tribal women, but also, they are much behind the non-tribal women in taking up the full course of ANC. More than 55\% of tribal women did not receive a single dose of TT vaccine during their last pregnancy compared to $37 \%$ of nontribal women. Again, in the case of tribal women, only $29 \%$ received the complete TT injection (all three doses), whereas in the case of non-tribal women, the percentage goes to 48 . It is recommended that immediate attention should be paid towards tribal women so that more pregnant women are covered by TT vaccine in order to save them and their children from the most dangerous disease of tetanus. The findings also suggest that despite generally improving coverage of tetanus toxoid vaccination, the coverage for socio-economically disadvantaged women lags far behind that of the privileged women in Jharkhand.

Iron deficiency anemia is the most common

Table 3: Exposure to antenatal check-ups, tribal and non-tribal women, Jharkhand, 1998-99

\begin{tabular}{|c|c|c|c|}
\hline Components of antenatal check-ups & Tribal women & Non-tribal women & Total \\
\hline \multicolumn{4}{|l|}{ Antenatal Measurement/Tests } \\
\hline General checkup & 49.7 & 56.7 & 55.3 \\
\hline Blood pressure checked & 37.0 & 60.0 & 55.3 \\
\hline Blood test & 41.3 & 59.8 & 56.0 \\
\hline Urine test & 28.3 & 53.3 & 48.2 \\
\hline Abdomen examined & 53.2 & 70.0 & 66.5 \\
\hline Internal examination & 14.9 & 26.1 & 23.8 \\
\hline X-ray & 0.0 & 2.2 & 1.9 \\
\hline Sonography & 0.0 & 6.7 & 5.3 \\
\hline \multicolumn{4}{|l|}{ Antenatal Advice } \\
\hline Diet & 63.0 & 69.4 & 68.1 \\
\hline Danger signs of pregnancy & 34.9 & 40.2 & 39.1 \\
\hline Delivery care & 39.1 & 45.6 & 44.2 \\
\hline Newborn care & 42.6 & 42.2 & 42.3 \\
\hline Family planning & 6.5 & 19.4 & 16.8 \\
\hline Number of births & 142 & 368 & 510 \\
\hline
\end{tabular}

Note: Table includes only for the most recent birth during the three years preceding the survey 
Table 4: Tetanus toxoid vaccination and Iron Folic Acid tablets or syrup consumption among tribal and non-tribal women, Jharkhand, 1998-99

\begin{tabular}{lccc}
\hline TT Vaccine and IFA supplementation & Tribal women & Non-tribal women & Total \\
\hline Has done ANC & 25.7 & 44.3 & 39.0 \\
Given iron folic acid tablets & 24.3 & 36.2 & 32.8 \\
Given enough tablets for at least three months & 73 & 89.2 & 85.8 \\
Consumed all tablets & 78.4 & 83.5 & 82.4 \\
TT injections given & 43.7 & 63.5 & 57.9 \\
Given all the three doses of TT injections & 28.8 & 48.4 & 44.2 \\
\hline
\end{tabular}

Note: Table includes only for the most recent birth during the three years preceding the survey

micronutrient deficiency in the world. Overall, about one-third of newborn children in India are of low birth weight. Therefore the provision of iron and folic acid (IFA) tablets to pregnant women to prevent nutritional anemia forms an integral part of the safe-motherhood services offered as a part of the MCH activities of the Family Welfare Programme (MOHFW, 1991) and now offered as a part of the RCH Programme. Table 4 also shows the status of IFA consumption among the tribal and non-tribal women in Jharkhand. 24\% of tribal women were given IFA tablets and among them $73 \%$ received enough tablets for at least three months. $78 \%$ of the tribal women consumed all the tablets given to them. However consumption of IFA tablets were higher among the non-tribal women.

(iv) Reasons for not Receiving Antenatal Check-ups: Table 5 explores the reasons for not receiving antenatal care among the tribal and nontribal women in Jharkhand. For $72 \%$ of the births to tribal mothers who did not have any antenatal check-ups, mothers did not consider having a check-up necessary or customary, compared to $65 \%$ of non-tribal women. Also $11 \%$ of tribal women reported that antenatal care service is either too far from their place or it is inconvenient for them to visit or they had no time to visit. Costs for obtaining health care services was reported by another $15 \%$ among the tribal women compared to $21 \%$ of non-tribal women. Lack of knowledge or familial resistance were the other reasons. These results suggests that there is a need to inform the mothers and families about the availability and benefits of antenatal checkups to help overcome traditional attitudes and other hurdles that prevent mothers specifically tribal mothers from seeking antenatal care for their pregnancies. Again, since about one-fourth of the reasons reported deal with the problems of accessibility and cost of services, utilisation of antenatal care services among women in general and tribal women in particular could also be increased by lowering direct and indirect costs, improving quality, and making services more accessible.

\section{Delivery Care}

(i) Place of Delivery: One of the important major thrust areas of the RCH Programme in India is to encourage and promote deliveries under proper hygienic conditions under the supervision of trained health professionals. Table 6 shows the place of delivery of the both tribal and non-tribal mothers in Jharkhand for their most recent birth. It is shocking to note that more than $92 \%$ of the most recent delivery among the tribal mothers had been taken place in their own home compared to $74 \%$ among the non-tribal mothers. In parent's home, $8 \%$ births took place among non-tribal mothers as compared to $3.3 \%$ among tribal mothers. Only about $5 \%$ of the deliveries of tribal mothers have been taken place in health facilities compared to $18 \%$ among the non-tribal women. Only $1 \%$ of the births among the tribal

Table 5: Reasons for not receiving antenatal check-ups, tribal and non-tribal women, Jharkhand, 1998-99

\begin{tabular}{lccc}
\hline Reasons for not receiving antenatal check-up & Tribal women & Non-tribal women & Total \\
\hline Not necessary/not customary & 72.4 & 65.5 & 67.9 \\
Costs too much & 15.2 & 20.7 & 18.8 \\
Too far/inconvenient/no time to go & 11.4 & 8.4 & 6.8 \\
Family did not allow/lack of knowledge & 1.0 & 1.0 & 5.8 \\
Other reasons & 0.0 & 0.6
\end{tabular}

Note: Table includes only for the most recent birth during the three years preceding the survey 
mothers took place in facilities operated by nongovernmental organisations or trusts. The corresponding figure for non-tribal mothers in Jharkhand stands at zero.

(ii) Assistance During Delivery: Table 7 provides information on assistance during delivery for the most recent birth among the tribal and non-tribal women in Jharkhand. Only 5\% of the recent births among tribal mothers has been conducted by a trained person whereas it is $17 \%$ among the non-tribal mothers. Thus in both the group, safe delivery is very less. It is distressing to note that $94 \%$ of the births among the tribal mothers has been attended by untrained persons compared to $82 \%$ among the non-tribal women. This, of course, is very dangerous to the life of the woman as well as of the child. Here there is an immediate need to sensitize the tribal women about this risk.

(iii) Delivery Characteristics: Table 8 shows the percentage of most recent births during the three years preceding the survey among the tribal and non-tribal women in Jharkhand. Based on the mother's report, $23 \%$ of the most recent birth in Jharkhand was by caesarian section. The proportion of deliveries by caesarian section was lower among the tribal women than the non-tribal women. In Jharkhand $29 \%$ of babies born to the tribal women were not weighed at birth compared to $27 \%$ among the non-tribal women. Even for babies that were weighed, more tribal mothers did not remember the weight. Among the children for whom birth weights were reported, less than one percent of tribal children weighed less than $2.5 \mathrm{~kg}$ at birth, as compared to a figure of $4 \%$ among non-tribal women.

More than $21 \%$ and $1 \%$ of births among the tribal women were of small size and very small size respectively, compared to $14 \%$ and $4 \%$ among the non-tribal women. Most of the births among the tribal and non-tribal women $(73 \%$ and $75 \%$ respectively) were of average size. A small proportion of babies among both the tribal and non-tribal women were reported large at the time of their birth (5\% and $7 \%$ respectively).

\section{Postnatal Care Among the Tribal and Non-Tribal Women in Jharkhand}

(i) Postpartum Check-ups: The health of a mother and her new born child depends not only on the health care she receives during her pregnancy and delivery, but also on the care she and the infant receive during the first few weeks after the delivery. Table 9 shows the percentage of non-institutional births for which a postpartum check-up was received. Among the births that were followed by a postpartum check-up, the table also shows the percentage with a check-up within two days of delivery (which is the most crucial period) and within one week of delivery. Only $11 \%$ of the births among the tribal women

Table 6: Place of delivery among the tribal and non-tribal women, Jharkhand, 1998-99

\begin{tabular}{lccc}
\hline Place of delivery & Tribal women & Non-tribal women & Total \\
\hline Health Facility/Institution & & & \\
$\quad$ Public & 0.7 & 6.4 & 4.7 \\
$\quad$ NGO/Trust & 1.3 & 0 & 0.4 \\
$\quad$ Private & 2.6 & 11.7 & 9.2 \\
Home & 92.1 & 73.6 & 78.8 \\
$\quad$ Own home & 3.3 & 8.4 & 6.9 \\
$\quad$ Parent's home & $\mathbf{1 4 2}$ & $\mathbf{3 6 8}$ & $\mathbf{5 1 0}$ \\
\hline
\end{tabular}

Note: Table includes only for the most recent birth during the three years preceding the survey

Table 7: Percentage distribution of births by attendant assisting during delivery, Jharkhand, 1998-99

\begin{tabular}{lccc}
\hline Delivery conducted by & Tribal women & Non-tribal women & Total \\
\hline $\begin{array}{l}\text { Any trained person } \\
\text { (Doctors/ nurse/midwife/other health professional) }\end{array}$ & 4.9 & 17.4 & 13.9 \\
$\begin{array}{l}\text { Any untrained person } \\
\text { (Traditional Birth Attend/ relatives and friends) }\end{array}$ & 94.4 & 82.1 & 85.5 \\
None & 0.7 & 0.5 & 0.6 \\
Number of births & $\mathbf{1 4 2}$ & $\mathbf{3 6 8}$ & $\mathbf{5 1 0}$ \\
\hline
\end{tabular}

Note: Table includes only for the most recent birth during the three years preceding the survey 
were followed by a check-up within two months of the delivery compared to $19 \%$ among the nontribal women. $59 \%$ of the check-ups took place within 2 days of births for tribal women as compared to $66 \%$ in the case of non-tribal women.

Table 9 also shows, the percentages of mothers, who received specific recommended components of postpartum care including an abdominal examination and advice on family planning, breastfeeding, and baby care. For 38\% of births among the tribal women, mothers who received a postpartum check-up also had their abdomen examined during the check-up, as compared to $29 \%$ for non-tribal women. Advice on breastfeeding and baby care was considerably more common among the tribal women $(56 \%$ and $63 \%$ cases respectively). Least important was the advice given on family planning, which was $19 \%$ among the tribal women and $24 \%$ among the nontribal women.

(ii) Postpartum Complications: Postpartum complications have been studied through two indicators like massive vaginal bleeding or very high fever at any time during the two months after delivery. Tribal mothers in Jharkhand reported of severe postpartum complications (massive vaginal bleeding as well as very high fever) for 4 percent of births and any symptom of postpartum complications for 23 percent of births. However postpartum complications were higher among the non-tribal women (Table 10).

(iii) Initiation of Breast-Feeding After the Birth of Last Child: Although breastfeeding is universal in India, very few children are put to breast immediately after birth. But among the tribal women $14 \%$ of the children began breastfeeding within one hour of birth and $22 \%$ started breastfeeding within one day of the birth. Most of the tribal as well as non-tribal children began breastfeeding more than one day after their birth (64\% and 69\% respectively). However about twothirds of both tribal (65\%) and non-tribal women $(64 \%)$ squeezed the first milk from the breast before they began breastfeeding (Table 11). This practice is contrary to recommendations for feeding infants formulated by the WHO.

Table 8: Characteristics of births among tribal and non-tribal women, Jharkhand, 1998-99

\begin{tabular}{|c|c|c|c|}
\hline Characteristics of birth & Tribal women & Non-tribal women & Total \\
\hline Percentage delivered by caesarian section & 20.0 & 23.0 & 22.7 \\
\hline \multicolumn{4}{|l|}{ Birth Weight } \\
\hline$<2.5 \mathrm{~kg}$ & 0.6 & 1.6 & 1.3 \\
\hline $2.5 \mathrm{~kg}$ or more & 1.2 & 3.7 & 3.0 \\
\hline Not weighed & 28.9 & 27.0 & 27.6 \\
\hline Don't know/missing & 69.2 & 67.7 & 68.2 \\
\hline Total percent & 100.0 & 100.0 & 100.0 \\
\hline \multicolumn{4}{|l|}{ Size at Birth } \\
\hline Large & 4.6 & 6.8 & 6.2 \\
\hline Average & 73.0 & 74.9 & 74.4 \\
\hline Small & 21.1 & 14.4 & 16.3 \\
\hline Very small & 1.3 & 3.9 & 3.2 \\
\hline Total percent & 100.0 & 100.0 & 100.0 \\
\hline Number of births & 142 & 368 & 510 \\
\hline
\end{tabular}

Note: Table includes only for the most recent birth during the three years preceding the survey ( ) Based on less than 25 cases

Table 9: Postpartum checkups among tribal and non-tribal women, Jharkhand, $1998-99$

\begin{tabular}{|c|c|c|c|}
\hline Postpartum check-ups & Tribal women & Non-tribal women & Total \\
\hline $\begin{array}{l}\text { Percentage with a postpartum check-up } \\
\text { within two months of birth }\end{array}$ & 11.2 & 18.5 & 16.4 \\
\hline Percentage seen within two days of birth & 58.8 & 66.2 & 64.8 \\
\hline Percentage seen within one week of birth & 41.2 & 33.8 & 35.2 \\
\hline \multicolumn{4}{|l|}{ Components of Postpartum Check-up } \\
\hline Abdominal examination & 37.5 & 29.4 & 31.0 \\
\hline Family planning advice & 18.8 & 23.5 & 22.6 \\
\hline Breastfeeding advice & 56.3 & 51.5 & 52.4 \\
\hline Baby care advice & 62.5 & 52.9 & 54.8 \\
\hline Number of births & 142 & 368 & 510 \\
\hline
\end{tabular}

Note: Table includes only for the most recent birth during the three years preceding the survey 


\section{CONTRACEPTIVE USE AND PROBLEM AND REPRODUCTIVE HEALTH PROBLEMS}

\section{Contraceptive Use and Problems}

Table 12 shows the current contraceptive usage and problem among tribal and non-tribal currently married women in Jharkhand. $15 \%$ of the currently married tribal women were currently using some method of contraception and about $31 \%$ of the non-tribal women were doing so. $1 \%$ of the tribal women were using any traditional method and $3 \%$ were using other methods like folkloric methods. Modern methods of contraception were used by only $1 \%$ of tribal women and $3 \%$ of non-tribal women. Again, among the current contraceptive user, terminal method were used by $9 \%$ of tribal women compared to $25 \%$ of non-tribal women. Also among the women who are currently using contraception, $15 \%$ of the tribal women had some problem compared to $27 \%$ among the non-tribal women.

\section{Reproductive Health Problems}

Absence of reproductive tract infections (RTIs) is essential for the reproductive health of both women and men and is critical for their ability to meet their reproductive goals. Table 13 shows the prevalence of different types of reproductive health problems among the tribal and non-tribal women in Jharkhand. The reproductive health situation seems to be better among the tribal women in Jharkhand than their non-tribal counterparts. Overall $43 \%$ of tribal women have any reproductive health problem compared to $46 \%$ among non-tribal women. Of all reproductive health problems, urinary tract infection is higher among the tribal women $(28 \%)$ than non-tribal women $(26 \%)$. Among the currently married tribal women, the symptom of bleeding after intercourse is higher (4\%) than the non-tribal women $(2 \%)$.

Table 10: Postpartum complications, which occurred to tribal and non-tribal mothers within two months after the delivery, Jharkhand, 1998-99

\begin{tabular}{lccc}
\hline Postpartum complications & Tribal women & Non-tribal women & Total \\
\hline $\begin{array}{l}\text { Any postpartum complications } \\
\text { (Massive vaginal bleeding or very high fever) }\end{array}$ & 23.2 & 25.8 & 25.1 \\
$\begin{array}{l}\text { Severe postpartum complications } \\
\text { (Massive vaginal bleeding and very high fever) }\end{array}$ & 4.2 & 9.8 & 8.2 \\
Number of births & $\mathbf{1 4 2}$ & $\mathbf{3 6 8}$ & $\mathbf{5 1 0}$ \\
\hline
\end{tabular}

Note: Table includes only for the most recent birth during the three years preceding the survey

Table 11: Initiation of breastfeeding after childbirth among tribal and non-tribal women, Jharkhand, 1998-99

\begin{tabular}{|c|c|c|c|}
\hline Initiation of breastfeeding & Tribal women & Non-tribal women & Total \\
\hline Percentage started breastfeeding within one hour of birth & 13.8 & 7.6 & 9.4 \\
\hline Percentage started breastfeeding within one day of birth & 22.1 & 24.2 & 23.6 \\
\hline Percentage started breastfeeding more than one day of birth & 64.1 & 68.3 & 67.1 \\
\hline Percentage whose mother squeezed first milk from breast & 65.3 & 64.1 & 64.6 \\
\hline Number of births & 142 & 368 & 510 \\
\hline
\end{tabular}

Note: Table includes only for the most recent birth during the three years preceding the survey

Table 12: Current contraceptive usage and problems among tribal and non-tribal women, Jharkhand, 1998-99

\begin{tabular}{|c|c|c|c|}
\hline Current contraceptive usage and problem & Tribal women & Non-tribal women & Total \\
\hline Currently using any method of contraception & 14.9 & 30.8 & 26.3 \\
\hline Using terminal method & 9.1 & 24.6 & 20.1 \\
\hline Any modern method (Pill/IUD/Condom) & 0.8 & 3.4 & 2.7 \\
\hline Any traditional method & 1.3 & 0.9 & 1.0 \\
\hline Other methods (folkloric method) & 3.2 & 0.9 & 0.5 \\
\hline Using no method & 85 & 68.9 & 73.6 \\
\hline Problem with the current method & 14.5 & 26.8 & 26.3 \\
\hline Number of women & 469 & 1145 & 1614 \\
\hline
\end{tabular}


Table 13: Symptoms of reproductive health problems among tribal and non-tribal women, Jharkhand, 1998-99

\begin{tabular}{|c|c|c|c|}
\hline Reproductive health problems & Tribal women & Non-tribal women & Total \\
\hline Any abnormal vaginal discharge & 29.4 & 31.4 & 30.8 \\
\hline \multicolumn{4}{|l|}{ Vaginal Discharge Accompanied $B y^{l}$ : } \\
\hline Itching or irritation & 17.5 & 18.3 & 18.1 \\
\hline Bad odour & 11.4 & 13.6 & 12.9 \\
\hline Severe lower abdominal pain ${ }^{2}$ & 19.2 & 20.5 & 20.1 \\
\hline Fever & 7.8 & 10.3 & 9.6 \\
\hline Other problem & 7.8 & 9.4 & 8.9 \\
\hline Symptoms of a urinary tract infection ${ }^{3}$ & 28.4 & 25.9 & 26.6 \\
\hline Any abnormal vaginal discharge or symptoms & & & \\
\hline of a urinary tract infection 3 & 41.9 & 41.7 & 41.8 \\
\hline${ }^{4}$ Painful intercourse (often) & 12.1 & 13.0 & 12.8 \\
\hline${ }^{4}$ Bleeding after intercourse (ever) ${ }^{2}$ & 3.7 & 2.3 & 2.7 \\
\hline Any reproductive health problem & 43.4 & 45.5 & 44.9 \\
\hline Number of women & 469 & 1145 & 1614 \\
\hline
\end{tabular}

${ }^{1}$ Ever-married woman, ${ }^{2}$ Not related to menstruation, ${ }^{3}$ Includes pain or burning while urinating or more frequent or difficult urination, ${ }^{4}$ Currently married women

\section{NUTRITION AND ANEMIASTATUS}

\section{Nutritional status}

Physical measurements such as height, weight and body mass index reflect the total nutritional status over a lifetime. Nutritional status is also a very important indicator of assessing maternal health. Table 14 shows among the tribal and non-tribal women, mean height, percentage with height below $145 \mathrm{~cm}$, mean body mass index (BMI), and percentage with specified levels of BMI in Jharkhand. The mean height among both tribal and non-tribal women in Jharkhand is $150 \mathrm{~cm}$, which is one point less than all India average. 17\% of tribal women are below $145 \mathrm{~cm}$ of height compared to $19 \%$ among the non-tribals. The mean BMI for tribal women in Jharkhand is 19.1 compared to 19.5 among the non-tribal women. Though more than half of the women in Jharkhand have a BMI between 18.5 -
$25 \mathrm{~kg} / \mathrm{m}^{2}$ (normal condition), still about $41 \%$ of both tribal and non-tribal women in Jharkhand, have a BMI of less than $18.5 \mathrm{~kg} / \mathrm{m}^{2}$ which indicates a high prevalence of chronic nutritional deficiency.

\section{Anemia status}

Anemia is characterised by a low level of hemoglobin of the blood. In India, anemia affects an estimated $50 \%$ of the population (Seshadri 1998). Table 15 shows the status of anemia among the tribal and non-tribal women of Jharkhand. Tribal women in Jharkhand have a high prevalence of anemia with about three-fourth of women having any type of anemia compared to $64 \%$ among the non-tribal women. About 3\% of the tribal women in Jharkhand are severely anemic compared to only $1 \%$ among the nontribal women. Otherwise also 30\% and 39\% of tribal women in Jharkhand are either moderately

Table 14: Nutritional status of tribal and non-tribal women, Jharkhand, 1998-99

\begin{tabular}{lccc}
\hline Nutritional status & Tribal women & Non-tribal women & Total \\
\hline Height & & & \\
Mean height (cm) & 149.9 & 149.7 & 149.8 \\
Percentage below 145 cm & 17.1 & 19.1 & 18.5 \\
Weight-for-Height* & 19.07 & 19.53 & 19.41 \\
Mean body mass index (BMI) & 40.9 & 41.4 & 41.3 \\
Percentage with BMI <18.5 & 57.0 & 54.6 & 55.3 \\
Percentage with BMI 18.5 - 25 & 0.9 & 3.4 & 2.7 \\
Percentage with BMI 25 - 30 & 1.2 & 0.6 & 0.7 \\
Percentage with BMI > 30 & $\mathbf{4 6 9}$ & $\mathbf{1 1 4 5}$ & $\mathbf{1 6 1 4}$ \\
\hline
\end{tabular}

*Excludes women who are pregnant. The Body mass index (BMI) is the ratio of the weight in kilograms to the square of the height in meters $\left(\mathrm{kg} / \mathrm{m}^{2}\right)$ 
Table 15: Anemia status among tribal and non-tribal women, Jharkhand, 1998-99

\begin{tabular}{lccc}
\hline Percentage of women with & Tribal women & Non-tribal women & Total \\
\hline Any anemia & 74.8 & 64 & 67.2 \\
Mild anemia & 39.1 & 42.5 & 41.5 \\
Moderate anemia & 33.1 & 20.3 & 24.0 \\
Severe anemia & 2.6 & 1.2 & 1.7 \\
Number of women & $\mathbf{4 6 9}$ & $\mathbf{1 1 4 5}$ & $\mathbf{1 6 1 4}$ \\
\hline
\end{tabular}

anemic or mild anemic. This is a major cause of concern.

\section{SUMMARY AND CONCLUSION}

The above discussion clearly brings out the differential in the health care and health condition among the tribal women and non-tribal women in Jharkhand. The findings reveals that in each and every socio-economic, demographic as well as health parameters, the tribal women a very much poor than the non-tribal women. Malnutrition is pervasive among tribal women. There is also a high prevalence of anemia among the tribal women in Jharkhand. The utilization of maternal health care is also very less among the tribal women than non-tribal women in Jharkhand. Use of modern methods of contraception is also significantly less among the tribal women than the non-tribal women. All these will likely to have not only an adverse long-term impact on their own health and well being but also on their children.

In India, the National Health Services have often neglected the tribal people in general and tribal women in particular. In addition to the social and economic factors contributing to the low health status of this underprivileged group, cultural factors might also play a role. In 1982, with the establishment of the National Health Policy, the Indian government declared the need to improve the health status and quality of life of the underprivileged groups. But programs to improve the health status and quality of life of underprivileged groups cannot succeed unless they form part of a larger effort to bring about and overall transformation of society (Basu, 1992).

The interventions for improving the health status of women under the Government of India's Child Survival and Safe Motherhood Program, has not significantly able to improve the services for women specially in the tribal areas of Jharkhand. Therefore there is an urgent need to create awareness about this at the community as well as at an individual level. In order to improve the health status of the tribal women in Jharkhand, the health care delivery system should be designed effectively to cater to the specific needs of the tribal women during pregnancy and at childbirth by ensuring their personal involvement. Health interventions must focus on tribal culture, medical training of the tribal people, and a knowledgeable health care delivery system catering to the needs of tribal women and the child.

\section{REFERENCES}

Basu, S. 1992. Health and Culture among the underprivileged groups, Health For The Millions. Feb-Apr; 18(1-2): 23-4.

Basu, S.K. 1994. A health profile of tribal India, Health For The Millions. Apr; 2(2):12-4.

Basu, S.K., A. Jindal and G. K. Kshatriya. 1990. The determinants of health seeking behaviour among tribal populations of Bastar District, Madhya Pradesh. South Asian Anthropologist,11(1): 1-6.

International Institute for Population Sciences (IIPS), \& ORC Macro. 2000. National Family Health Survey (NFHS-2), 1998-99: India. Mumbai: International Institute for Population Sciences.

International Institute for Population Sciences (IIPS), \& ORC Macro. 2001. National Family Health Survey (NFHS-2), 1998-99: Jharkhand. Mumbai: International Institute for Population Sciences.

Kanitkar T and R. K. Sinha. 1988. A Report on Demographic Study of Tribal Population in Santhal Pargana in Bihar and Phulbani and Kalahandi Districts in Orissa, Bombay. India, Mumbai: International Institute for Population Sciences, 46p.

Ministry of Health and Family Welfare. 1998. Manual on Community Needs Assessment Approach in Family Welfare Programme. New Delhi: Department of Family Welfare, MOHFW.

Ministry of health and Family Welfare. 1997. Reproductive And Child Health Programme: Schemes for Implementation. New Delhi: Department of Family Welfare, MOHFW.

Population Council. 1999. Reproductive Tract Infections. A Set of Fact Sheets. Bangkok: Population Council.

Seshadri, Subadra. 1998. A Data base on Iron Deficiency Anemia (IDA) in India: Prevalence, Causes, consequences and Strategies for Prevention. Vadodara: The Maharaja Sayajirao University of Baroda. 